\title{
Role of Organisational Culture of the University in Formation of Psychological Readiness of Students to Assertive Behaviour
}

\author{
Myron Y. Varii, ${ }^{\#,}$, Olena A. Leshchynska ${ }^{\#}$ and Yuliana M. Terletska ${ }^{\#}$
}

\author{
Lviv Polytechnic National University, Lviv, Ukraine
}

\begin{abstract}
Objective: the primary purpose of the work is to study the role of organisational culture of the modern Ukrainian university in the process of formation of psychological readiness of students to assertive behaviour.

Background: Scientific and public discussion about reforming the system of higher education requires deeper research of the influence of university organisational culture on forming not only professional but also personal skills and abilities that make this research relevant.

Method: The selection has 180 respondents from all departments and institutions of university and has been balanced by gender and age. This was the psychosemantic research.

Results: To collect the data, suggestions regarding resistance to undesirable influence were used developed by $P$. Zimbardo and S. Andersen, ten assertive rules of personality developed by M.J. Smith and the author's survey "Confession of a sad student". Obtained data were represented using the factor analysis. Assumptions concerning the normal distribution were checked using the statistical criteria of Bartlett of the mathematical, statistical package SPSS 14.

Conclusion: The obtained factor structure showed that it is possible to speak of domination in the student environment of the tendency to immature self-affirmation along with a readiness to conquer that can be explained by the inadequate conditions of organisational culture to form assertiveness of student.
\end{abstract}

Keywords: Assertive behaviour, psychosemantic analysis, organizational culture of university.

\section{INTRODUCTION}

The prompting to conduct this research was, from the one side, a large number of publications on the necessity to reform the higher education, about the consequences of those reforms already taking place and about the differences between the national higher education and education in the leading institutions of Western Europe and North America [1]. From the other side, those discussions in the West show that their organisational culture of university as a social institution is also transforming [2]. Thus, thoughts about the role of the highest education and science in modern society create many topics for discussion, research, and many hypotheses. From the other side, numerous discussions with postgraduates, colleagues, students of advanced training courses about a role of higher education in their lives have led authors to the following conclusion: regardless of whether a person had professional experience, what was his/her majority in university, even after a while when knowledge obtained in university has outdated, a human still has the habit of studying, of gaining needed knowledge, to mobilise internal resources, to set goals and withstand pressure and protect professional and life position. All mentioned

*Address correspondence to this author at the Lviv Polytechnic National University, Lviv, Ukraine; Tel: +380322582227;

E-mail: myr-varii@ust-hk.com.cn

${ }^{\#}$ These authors are equally contributed. above form not so much as a result of student study of individual training courses, but due to the influence of the organizational culture of the university. That is why we think that the formation of the psychological readiness of students to assertive behaviour is one of the components of the mission of organisational culture of the university.

Exactly this narrow but important matter on the role of organisational culture of modern Ukrainian university in the process of formation of psychological readiness of students to assertive behaviour is the purpose of this empirical research, being more accurate - testing of the following hypothesis: psychological readiness of a student to assertive behaviour forms if there are appropriate conditions in organisational culture of university to interact constructively with a teacher in the process of educational activity. The concept of organisational culture helps to understand and analyse triggers that transform the educational organisation into university or school with structural, developed, and efficient work. It also determines possible ways for universities and schools to improve management and develop strategies for improvement and reform. In our view, the style of the interaction of students and teachers is one of the most important components of organisational culture of the university.

Our research aims to determine the features of interaction student-teacher in Ukrainian universities 
and the level of students' psychological readiness to assertive behaviour.

\section{MATERIALS AND METHODS}

Our research is built on the thesis of Ch. Osgud about the relevance of connotative meanings to the syncretic mechanism of categorisation that operates at the level of "deep semantics". This level is involved in the early stages of presentation, an object to subject when emotional and perceptual characteristics are presented to the consciousness in unbreakable unity. The main method to reveal connotative meaning is the method of semantic differential, and the operational form of its presentations is a multidimensional semantic space. Numerous achievements within the methodology of semantic scaling proved impressive intercultural and interpersonal stability of the structure of connotative meaning, which is the dimension of connotative "space".

Since in the framework of psychosemantic approach based on the works of J. Kelly, Ch. Osgud [3, 4], many of various materials have been accumulated that related to structural and content characteristics of the semantic structure of the consciousness of different levels of reflection, this gives an opportunity to study adequately social settings of different communities and individual content links as a component of a subjective world picture of a person. Psychosemantic approach implies research of structural, functional, and content features of social settings basing on features that dominate at a certain level of the form of sign mediation. Building subjective semantic spaces that allow revealing the most important factors using which a person conducts a categorical analysis of some social phenomenon and is such a method.

To some extent, it will enable solving the problems of research of the deep structures of the human psyche, in many respects responsible for regulating its behaviour in society. Experience of using psychosemantic methods demonstrates that with their help it is possible to build various systems of determination, find different communities revealing emotionally saturated, poorly structured representations of a human about himself/herself and other people, different social values and, in general, of objects that are deeply personal.

The study took place in 2017-2018 academic years at Vasyl Stefanyk Precarpathian National University in all departments and at all university institutes by deep structural interview. Specially calculated structure of the selection and its size (180 respondents of all departments and institutions of university balanced by gender and age) is representative and allows speaking of social settings of students of the whole university (Table 1). Statements of the survey $(n=42)$ were selected according to the main purpose of this study. Therefore, content statements were selected in such a way that, in general, the survey reflects students' attitudes to organisational culture of university and level of assertiveness.

The stimulus material used as indicators suggestions on resistance to undesirable influence developed by F. Zimbardo and C. Andersen [5], recognised by American Psychological Association (APA) and 10 assertive rules of a personality developed by M.J. Smith [6]. The author's survey "Confession of a sad student" was also used. It contains a set of statements that describe the extreme negative state of a student at the higher education organisation. All statements of the survey were formulated as a result of focus groups with students on the problems of studying in university, in the process of studying the course "Psychology of Higher Education" in the Master's program.

Table 1: Characteristics of Age Groups

\begin{tabular}{|c|c|c|c|}
\hline Age & Number of women & Number of men & Total number of persons \\
\hline \hline $17-18$ & 15 & 8 & 23 \\
\hline 19 & 18 & 12 & 30 \\
\hline 20 & 14 & 3 & 41 \\
\hline 21 & 19 & 4 & 10 \\
\hline 22 & 6 & 10 & 30 \\
\hline 23 & 20 & 12 & 22 \\
\hline 24 & 17 & 4 & 29 \\
\hline
\end{tabular}


In the process of formulating statements, the following was taken into account: adaptation problems of a student can be caused based on individual features and as a result of features of organisation of the educational process. In order to make this confession more fun, a respondent is proposed to write at the beginning of each sentence "often", "sometimes", or "never" according to own feelings. Obtained results have been represented using factorial analysis. The basis for using factorial analysis was the normal distribution of results of tests of respondents. Assumptions about normal distribution were checked using the statistical criteria of Bartlett of the mathematical-statistical package SPSS 14 [7].

All procedures performed in studies involving human participants were in accordance with the ethical standards of the institutional and national research committee and the 1964 Helsinki declaration and its later amendments or comparable ethical standards. A study was approved by the Central Ethics Committee of the Ministry of Health of Ukraine, December 24, 2019, No 1678-O. Informed consent was obtained from all individual participants included in the study.

\section{RESULTS}

Factorial analysis has identified seven factors, the total variance of which exhausts $52.2 \%$. To determine a fact of statistical dependence between mentioned factors and some characteristics of respondents, the method of two-dimensional analysis has been used with the implementation of text $x^{2}$, contingency tables, and elucidation of statistical criteria for them. The results of the analysis have shown that factors correlate with the specified characteristic. Thus, contingency tables fields determine the big value of criterion $\mathrm{x}^{2}(\mathrm{p}<0.01$, in some cases, $\mathrm{p}<0.1)$.

Factor 1 "Psychological readiness to be conquered" (contribution to total dispersion 10.2\%). Statements included in this factor describe people who think that they should be careful and sensitive to others' needs insomuch that they even must "read the minds of others". They feel responsible for their behaviour so much that they have to report to others, explain every action, and apologize for actions; they must be attentive and emotional to everything that is happening in the world; otherwise, they risk looking inhuman indifferent. They admit having a great need to be loved and treated nicely. Also, these people are characterised that they can be very upset if, because of changing their original plans, someone will consider them inconsistent. Of course, they do not think that they have the right to apologise and explain their behaviour in such a situation. So, the statements: "I am practising phrases: "I made a mistake", "I'm sorry", "I was wrong ..." and I learned from this mistake", look not so much as a testimony of personal maturity and self-criticism, but as a confirmation of subordination and obstinacy.

This factor involves indicators of readiness to become dependent on other people that show unawareness of their own psychological boundaries, desire to please other people, to be pleasant in communication. All these statements in common speak of the ideal image of self as "I am as you want". Recognition of everything that parents wanted to see when they brought up a polite girl or obedient boy. And though respondents of the survey are adults, they deny their right to inner freedom, to personal psychological boundaries, thereby open themselves to uncontrolled external intrusion. This position demonstrates traditionally Ukrainian upbringing that requires children to obey their parents and elders obediently. The appropriateness of such upbringing strategies is very controversial. However, it should be acknowledged that such settings make a human open and unprotected to any rouge that may decide to parasite on him or her.

Factor 2 "Surface assertiveness" (contribution to total dispersion of $8.9 \%$ ). Statements included in factor 2 describe students who have joined the declaration of principles of assertive behaviour and insist on having the right to say "I do not understand you", right to make mistakes and be responsible for mistakes, having the right to say "I do not know", to change their mind, to make illogical decisions and to say "I am not interested". This position looks attractive in the eyes of modern Ukrainian students, but it appears that this looks more like a declaration than a real state.

Factor 3 "Academic anxiety" (contribution to total dispersion of $7.6 \%$ ). Statements that included in this bipolar factor describe people who admit fear of unpredictable, contradictory demands of teachers, they see future exams as an insurmountable obstacle, they are afraid to speak in front of an audience, consider themselves pessimists, feel the tension in conflict situations through learning, and sometimes they also have a depressed mood. Also, this group of respondents believes that they do not have the right to be independent of others' benevolence and their good attitude towards them. In return, they consider it necessary to take one point of view and not change it, if one has been expressed. 
This factor involves indicators from the "confession of a sad student", the content of which is the interaction of a student with a teacher and organisational culture of the university in general. Configuration of indicators of this factor demonstrates that organisational culture of the modern university is going through a spontaneous, forced transformation in crisis form that is not aware by both participants of the process - teachers and students - and its management. The driving forces of these transformations are beyond university and belong to more robust social and civilizational transformations such as information era, globalisation, change of trends in educational technologies, restructure of the employment system, and employment. Mentioned above is reflected in hidden conflicts between a student and a teacher that can be illustrated by following examples: a teacher, who by an old habit considers himself or herself a carrier of exclusive professional knowledge, requires the student to study the textbooks of his authorship and nothing else; a teacher, who ignores technical progress, requires the rewriting of textbooks by hand and also requires writing lecture notes in the same way, writing course papers and abstracts. Students, in their turn, require the right to use all available sources and information technologies. In this, they do not hesitate to use smartphones on exams.

Factor 4 "Unbearable power of teachers" (contribution to total dispersion of 7.5\%). Statements included in this factor describe students who are worried about endless academic debts, who seem to have lost control over their stud, who cannot come to a mutual understanding with teachers. The content of the factor indicates students' perception of the teacher primarily as a figure of power, unlimited power, for which there are no levers of influence, unpredictable and threatening, the one that suppresses and generates a pessimistic attitude life. "Support" of this feeling is also disagreement of these students with the statement that illegal power should always be discarded, discouraged, and exposed. Explanation of such a state of students is that organisational culture is built in such a way that almost eliminates the student's ability to make his personal choice of a teacher or training course in the learning process.

Factor 5 "Adaptation to conditions of forced unpredictability" (contribution to total dispersion 7.3\%). Statements included in this factor describe students who, from the one side, admit that it is not necessary to follow logic, rationality, to be a know-it-all; this demonstrates an adequate attitude to human nature, understanding that there are no supermen. But from the other side, they consider that they cannot be mistaken, feel guilty because of this, do not want to disappoint their loved ones, and do not have the right to independently evaluate own behaviour, thoughts, and emotions and be responsible for consequences. It is also important to note that these students feel that they do not have enough time to work well. It is wellknown that creation of conditions when a person feels a deficit of time leads to numerous mistakes and misses in an educational activity that causes shame and feeling of guilt. Since the degree of physical, emotional, and intellectual load on the physiology and psychology of the student is not taken into account when making a schedule, there is nothing strange here. In the schedule, math tests may follow physical education.

Factor 6 "Psychological readiness to assertive behaviour" (contribution to total dispersion 5.5\%). Statements included in this factor describe people who do not believe in simple solutions of complicated personal, social and political problems, who have inner psychological freedom that is based on awareness of own psychological boundaries and readiness to defend them even at the expense of spoiled relationships, losses in money, and in time, both in efforts and in selfesteem. They are sensitive to situational requirements, no matter how insignificant they may seem (social roles, uniforms, symbols of power, titles, group pressure, rules, duties, and obligations). Sometimes, they act untypically, change their usual role and personal image, study to respond adequately to refusal, strive for manifesting themselves, and see differently. It is possible to say that it is about students' mature personality, which is described by this factor. However, there is excessive dependence on significant others because they think that they have more obligations towards people and some institutions than themselves, so they have to sacrifice themselves and adapt.

Factor 7 "Mature self-sufficiency" (contribution to total dispersion of 5.2\%). Statements included in this factor describe people who do not seek to quickly repay their guilt, are tolerant of guilt as part of their human nature, and are not going to improve it through the ways that others offer. They consider that there is no such thing as true, unconditional love from unknown people, because love, friendship, and trust are manifested over time and require a certain work and duties from both parties. They avoid situations, which are unusual to them and deny control and freedom. 
However, they feel guilty when on weekends they do nothing at home, and in the morning of a workday, they often do not know what to do. Also, this category of students considers that they should not unceremoniously and independently of others evaluate themselves and their behaviour.

To complete the analysis, it is necessary to consider the percentage distribution of students' responses by the most content indicators such as power, sympathy, infantilism, and maturity.

\section{Power}

"Legal power deserves respect and sometimes our obedience, but illegal power should always be discarded, discouraged and exposed". In this case, only $41 \%$ of students are confident that it is necessary to resist illegal requirements to obey, $59 \%$ are not confident or even disagree. Thus, it shows the low level of readiness for assertive behaviour.

\section{Sympathy}

"I think there is no such thing as true, unconditional love from strangers; love, friendship, and trust are manifested over time and certainly require a certain work and obligations from my side". Only $44 \%$ are aware that sympathy of strangers that has aroused out of nowhere is not worth to be trusted, on the contrary, it should raise suspicion, but $55 \%$ do not understand this and even disagree.

\section{Infantilism}

"I do not believe in simple solutions of complicated personal, social and political problems". Only 33\% of students do not believe in simple solutions. This means they admit that they live in a complicated world, in which everything is interconnected and complicated problems require knowledge, patience, and perseverance. However, $67 \%$ doubt it or consider it wrong. Therefore, they are ready to propagate various radical ideas or to support them. This indicator points to the limit, where assertiveness becomes youthful maximalism and commitment to radical decisions.

\section{Maturity}

"If a promise I gave restricts my freedom of actions and I suffer because of disorder with myself, then I am ready to lose money, time, efforts, and self-respect to change a situation". Only $31 \%$ of students are ready to admit mistaken promises, to understand the reason of discomfort they feel as a result of these mistaken promises and find the strength and courage to rectify a situation. However, $69 \%$ of their peers doubt the necessity of such actions or know for sure that they are not ready to do this.

We advocate that readiness to assertive behaviour is the component of a more complicated personal formation, which is personal maturity that is being formed throughout life. So, results show that only onethird of students demonstrated readiness to mature personal decisions, but one-third revealed radical settings.

It is important to note that a mature person's selfaffirmation is socially accepted, safe, and strategically justified when self-affirmation of an infantile person may lead to personal, social, and political problems. The obtained factor structure shows that at the moment, it is possible to speak of domination in the student environment of the tendency to immature selfaffirmation along with a readiness to conquer. It is worth remembering that in student age, personal development is intensive, and membership in different communities (professional, cultural, public, political) plays an important role, but organisational culture of the university has the leading role.

The survey "Confession of a sad student": S sometimes, $\mathrm{O}$ - often, $\mathrm{N}$ - never. Results of the survey in percentage:

1. $\mathrm{S}-42 \%, \mathrm{O}-15 \%, \mathrm{~N}-38 \%$ I am concerned about endless academic debts.

2. $\mathrm{S}-43 \%, \mathrm{O}-18 \%, \mathrm{~N}-34 \%$ In the morning after waking up, I do not know what to do.

3. $\mathrm{S}-45 \%, \mathrm{O}-46 \%, \mathrm{~N}-7 \%$ I do not have enough time to work well.

4. $S-47 \%, \mathrm{O}-16 \%, \mathrm{~N}-35 \%$ I feel guilty when I do nothing at home on the weekend.

5. S $-50 \%, O-20 \%, N-30 \%$ I see future exams as an insurmountable obstacle.

6. $S-46 \%, O-14 \%, N-40 \%$ I think of myself as a pessimist.

7. $S-56 \%, O-13 \%, N-31 \%$, I think I lost control over my study.

8. $\mathrm{S}-55 \%, \mathrm{O}-9 \%, \mathrm{~N}-33 \%$ I feel pressure in conflict situation through study. 
9. $\mathrm{S}-51 \%, \mathrm{O}-3.14 \%, \mathrm{~N}-44 \%$ I cannot come to a mutual understanding with teachers.

10. $\mathrm{S}-52 \%, \mathrm{O}-18 \%, \mathrm{~N}-27 \%$ I am afraid of the unpredictable, contradictory demands of teachers.

11. S $-44 \%, \mathrm{O}-17 \%, \mathrm{~N}-39 \%$ I am afraid of performing in front of an audience.

12. $\mathrm{S}-72 \%, \mathrm{O}-16 \%, \mathrm{~N}-11 \%$ Sometimes, I have a depressed mood.

Most of the indicators of the questionnaire received a neutral response - "sometimes". We were interested, which by the content statements would be accumulated at the extreme poles. The pole "often" includes the following statements: In the morning after waking up, I do not know what to do; I do not have enough time to work well; I see future exams as an insurmountable obstacle; I am afraid of unpredictable, contradictory demands of teachers. The pole "never" includes the following statements: I cannot come to a mutual understanding with teachers; I think of myself as a pessimist; I am concerned about endless academic debts. It was revealed that "often" students are worried about educational situations that are not dependent on them, but entirely dependent on the organisational culture of the university. It also was revealed that students often feel the deficit of time and suffer from unpredictability in the educational process. In return, at the pole "never" there are situations that depend on the students' personal qualities and do not strain them. They think of themselves as optimists, believe in their communicative skills and intellectual abilities.

\section{DISCUSSION}

Our thoughts are based on the fact that the main function of a university is to generate new ideas for progress. The second important function of a university is a social lift, search in all layers of young people who can potentially generate new ideas and technologies. The third important function of a university is forming the special type of personality of a professional who, in addition to professional knowledge, should have high moral development, responsibility, qualities of a leader, professional identity, assertiveness - in one word, the ability to serve the cause.

The most popular and cited determination of the culture belongs to E.H. Schein who specified the notion: "a pattern of shared basic assumptions that the group learned as it solved its problems of external adaptation and internal integration, that has worked well enough to be considered valid and, therefore, to be taught to new members as the correct way to perceive, think, and fell in relation to those problems" [8]. The conception of assumption had the key role in the early stages of the theory of organisational culture because, in the beginning, it developed on a psychological basis. That is why E.H. Schein characterised the organisational culture more as "the set of basic silent assumptions about what world is and what it should be, what values a group of people shares, and how their thoughts, feelings and, to some extent, their perception, and open behaviour are determined". E.H. Schein stressed that leaders have an important role in forming and strengthening the culture of their organisations. E.H. Schein, and everyone after him, emphasised that values, beliefs, and assumptions - invented, discovered, or developed - typically, shared and adopted and certainly respected by members of a certain organisation, should be interpreted as rules and norms that explain why and how this organisation forms and structures, functions and lasts [8].

G. Hofstede stated that organisational culture is about how people should behave, draws those lines in which certain personalities manage people, and it reveals through the following practices: rituals (collective events that can be technically optional, ceremonies, for example), heroes (people who have peculiarities, who are highly valued), symbols (words, gestures, pictures and valuable objects for those who share culture) [9]. The organisational culture of the higher educational institutions is of particular interest that is why works of lan I. McNay are relevant [10], who developed the model that describes organisational culture of higher educational institutions by two specific dimensions: form and intensity of control and focused on policy and strategy. The model of I. McNay reflects four quadrants that correspond to the following types of university organisational culture:

an enterprise that consists of strong policy and free operative control, focusing on a market, external possibilities and relations with parties concerned;

corporate that consists of strong political and operative control, the domination of higher management, executive power;

collegial that consists of free policy and free operative control, decentralisation, focusing on personal freedom; 
- bureaucratic that consists of free police and strong operative control, focusing on rules and precedents [10].

The authors of the presented study believe that organisational culture of the university is an especial case because it is based on the fact that the educational unit is a self-organised system that relies on principles of cognition and learning. Also, it is the platform for the relation of a different character: internal relation between management, workers, and students (the latter is consumers of educational service); external relations with graduated, potential students and their parents as well as employers as clients; and undoubtedly partnership and competition with other educational institutions. The complexity and variety of these relations condition necessities to study organisational culture of university depending on students' attitude to this and their participation.

Assertiveness is an important component of the structure of modern professionals' competency because intellectually difficult professions require confidence, responsibility, readiness for decision making, resistance to attempts of emotional pressure, and manipulation. Self-affirmation is the most important element of social skills. A person, who is capable of self-affirmation insisting on reasonable demand and behaviour in their own defence, considers the rights and interests of others and tries to avoid violation [11]. In general, self-affirmation is the human ability to express and protect their own ideas, interests, and feeling concerning a decent thing and without anxiety [12]. A person, who is self-affirmed, takes responsibility for their own behaviour and choice, has normal selfesteem and positive thoughts and attitude to himself/herself, and a person's behaviour is frank and honest to himself/herself [13]. This person can use communicative methods, which allow upholding selfesteem, that leads to happiness and pleasure [14].

Self-regulation is also an important factor that influences the academic achievement of students, emotional and affective development. Self-regulation is defined as mental efforts to control internal state, process, and functions to achieve higher goals. J. Cole, T.K. Longman, and R. Walker stated that skills of assertiveness include an ability to protect own rights, express thoughts, emotions, and beliefs by direct and honest means in order not to violate the rights of others [15]. Bad communication may establish unhealthy relations and increase psychological pressure. A.J. Lang and $P$. Jakowbdki stated that one of the key factors in interpersonal communication is the ability to use assertiveness correctly [16]. Since excessive selfconfidence can cause problems for a personality and her/his environment. Infantile dependence, which manifests itself in psychological readiness to be conquered, is considered the personal characteristics, contrary to assertiveness.

\section{CONCLUSIONS}

Universities train professionals who, in their work activity, should be ruled by not only management's orders but also professional directives and ethical codes of professions that imply necessity and ability to defend own professional position. Universities perform mentioned functions not through educational activity, but through creation in university respective organisational culture with the spirit of artistic freedom, the value of knowledge, respect for free thought. Also, it is necessary to note that the educational sector is conservative and should remain like this because most of the tasks are of strategical, not tactical character. This explains the tendency that organisational cultures of universities gravitate to conservative style. In return, the modern information era with new educational technologies, ideas of globalisation and liberalism, compels all without exceptions to make changes in higher education and the functioning of organisational culture. In our country, for university management, it has not become a tradition to model perspective ways of functioning of organisational culture. So, changes are spontaneous, more often on-demand of the ministry of education.

Obtained psychosemantic structure speaks of psychological readiness to be conquered, which may be a consequence of upbringing traditions in Ukrainian culture. Revealed by us, surface assertiveness may be caused by features of young age characteristic of rebellious moods. The big load of factors "Academic anxiety" and "Unbearable power of teachers" may be explained by the fact that the organisational culture of Ukrainian universities is going through the transformation of more spontaneously than plan character. Three following factors, "Adaptation to conditions of forced unpredictability", "Psychological readiness to assertive behaviour", "Mature selfsufficiency" mean insufficiently satisfied conditions of organisational culture of the university, but the process of formation of psychological readiness of students to assertive behaviour is still going on. Since our thoughts on organisational culture of the university are mediated by the results of the study of students, the following 
studies should research conditions of the and develop technologies for its optimisation to work in modern conditions.

\section{ACKNOWLEDGEMENTS}

None.

\section{REFERENCES}

[1] Bilyuk $\mathrm{OH}$. Personality of the teacher of the university as a factor of educational influence on the development of moral and value relations with students. Scientific Herald Mykolaiv VO. Sukhomlynskyi National University. Pedagogical Sciences 2010; 1(31): 51-59.

[2] Eagleton T. The slow death of the university. The chronicle of Higher Education, 2015. Available at: https://www.chronicle.com/article/The-Slow-Death-ofthe/228991?key=Smt2IgNgb3oWZHlqZDdCNDhROiY8MU4h MHAeYnonblxSEw\%253D\%253D\%253D\%253D

[3] Kelly J. Theory of personality. In Psychology of Personal Constructs. St. Petersburg: Rech 2000.

[4] Osgud Ch, Susi J, Tannenbaum P. Measurement value. In Semiotics and Artmetry. Moscow: Mir, 1972.

[5] Zimbardo F, Andersen S. Explanation of mind control: exotic and everyday manipulations of consciousness. Journal of Practical Psychologist 2000; 1/2: 8-34.

[6] Smith MJ. Training of self-confidence: A set of exercises to develop confidence. St. Petersburg: Rech 2002.
[7] Nasledov AD. Mathematical methods of psychological research. Analysis and interpretation of data. St. Petersburg: Rech 2004.

[8] Schein EH. Organizational culture and leadership. San Francisco: Jossey Bass, 2010.

[9] Hofstede G. Culture's consequences: Comparing values, behaviors, institutions, and organizations across nations. Thousand Oaks: Sage, 2001

[10] McNay I. Universities going international: Choices, cautions and conditions. In P. Blok (Ed.). Policy and Policy Implementation in Internationalisation of Higher Education. Amsterdam: EAIE, 1995.

[11] Gibson DE. Developing the professional self-concept: Role model construal's at early, middle and late career stages. Organization Science 2003; 24: 591-610. https://doi.org/10.1287/orsc.14.5.591.16767

[12] Lizarrage ML, Ugarte MD, Cardelle-Elawar M, Iriarte, MD. Enhancement of self-regulation, assertiveness, and empathy. Learning and Instruction 2003; 13: 423-439. https://doi.org/10.1016/S0959-4752(02)00026-9

[13] Morris AS, Silk JS, Steinberg L, Myers SS, Robinson LR. The role of the family context in the development of emotion regulation. Social Development 2007; 16(2): 361-388. https://doi.org/10.1111/j.1467-9507.2007.00389.x

[14] Bolton R. Psychology of human relationships. Tehran: Roshd Publication, 2007.

[15] Cole J, Logan TK, Walker R. Social exclusion, personal control, self-regulation, and stress among substance abuse treatment clients. Drug and Alcohol Dependence 2011; 113: 13-20.

https://doi.org/10.1016/j.drugalcdep.2010.06.018

[16] Lang AJ, Jakowbdki P. Responsible assertive behavior. Washington DC: Research Press, 1978.

\section{DOI: https://doi.org/10.6000/2292-2598.2020.08.03.27}

(C) 2020 Varii et al.; Licensee Lifescience Global.

This is an open access article licensed under the terms of the Creative Commons Attribution Non-Commercial License (http://creativecommons.org/licenses/by-nc/3.0/) which permits unrestricted, non-commercial use, distribution and reproduction in any medium, provided the work is properly cited. 